\title{
Soybean defense induction to Spodoptera cosmioides herbivory is dependent on plant genotype and leaf position
}

\author{
Marcelo Mueller de Freitas ${ }^{1}$ (D) Bruno Henrique Sardinha de Souza ${ }^{1} \cdot$ \\ Luciano Nogueira $^{1}$ Mirella Marconato Di Bello ${ }^{1} \cdot$ Arlindo Leal Boiça Júnior $^{1}$
}

Received: 30 August 2016/ Accepted: 24 July 2017/Published online: 4 August 2017

(C) Springer Science+Business Media B.V. 2017

\begin{abstract}
Plants have evolved a diverse array of defensive mechanisms against biotic and abiotic stresses, which can be either constitutive or inducible. Variation in plant-intrinsic factors such as the genotype and the leaf position coupled with insect herbivory can affect the expression of resistance to insects. We investigated if soybean defense induction triggered by Spodoptera cosmioides herbivory varies in function of the genotype and leaf position. This hypothesis was tested in two bioassays using leaf discs or entire leaflets collected from the upper and lower trifoliates of $S$. cosmioides-injured and uninjured V3-V4 soybean plants. We used one genotype that was constitutively resistant and one that was constitutively susceptible to $S$. cosmioides based on previous screening. Third-instar larvae were fed one of the treatments and assayed for leaf consumption, larval growth, and efficiency of conversion of ingested food. Genotype and leaf position significantly interacted with herbivory and affected soybean-induced resistance to $S$. cosmioides. Negative responses on S. cosmioides larvae consumption and growth rates were only observed when leaf material was originated from the upper soybean trifoliate. The susceptible soybean genotype did not exhibit induced resistance characteristics. Food offered as leaf disc was better at demonstrating induced resistance in previously injured soybean, whereas offering entire leaflet the induced effects were less pronounced. Here we
\end{abstract}

Handling Editor: Joe Louis.

Marcelo Mueller de Freitas

freitasmm@hotmail.com

1 School of Agricultural and Veterinarian Sciences, Department of Plant Protection, São Paulo State University (Unesp), Via de Acesso Paulo Donato Castellane, Jaboticabal, São Paulo 14884-900, Brazil provide new findings on soybean resistance by demonstrating that resistance induction to $S$. cosmioides herbivory is dependent on the plant genotype and leaf position where injury took place, with negative effects better evinced in bioassays using leaf discs than entire leaflets.

Keywords Black armyworm · Glycine max · Induced resistance $\cdot$ Optimal defense theory $\cdot$ Research methodology

\section{Introduction}

Plants have evolved sophisticated defense mechanisms against biotic and abiotic stresses, which can be either constitutive or inducible. Constitutive defenses are quantitative or qualitative inheritance of mechanisms that are constantly expressed in plants. These defenses are not the result of plant recognition of elicitors from stress factors. The constitutive defenses may be composed of either chemical substances, morphological structures, or both that hamper the utilization of the plant tissues by herbivorous insects (Kant and Williams 2013). These defenses are often directly correlated with changes in insects feeding preference, growth, and/or reproduction (Coley and Barone 1996; Karban and Baldwin 1997). Defenses that are the result of induced resistance are quantitative or qualitative inheritance of mechanisms related to changes in plant physiology and morphology triggered by the recognition of elicitors on the stressor agent. Among the main stimuli capable of triggering plant-induced defense responses are arthropod herbivory, mechanical injury, temperature, $\mathrm{CO}_{2}$, and water stress (Karban and Baldwin 1997; Agrawal 1998; Smith 2005). 
Induced resistance has been observed in several plant species of agricultural importance, including tomato (Thaler et al. 1996), rice (Hamm et al. 2010), wheat (ElWakeil et al. 2010), and soybean (Lin and Kogan 1990). Soybean has been used as a model plant for testing the negative effects of secondary metabolites such as phenolics (Bi and Felton 1995), flavonoids (Hoffmann-Campo et al. 2001; Piubelli et al. 2005), oxidative enzymes (Bi and Felton 1995; Souza 2014), and proteinase inhibitors (Underwood et al. 2002) on growth and reproduction of herbivorous insects. Previous studies have reported soybean induced resistance towards insect herbivory (Lin and Kogan 1990; Kogan and Fischer 1991) and mechanical injury (Lin et al. 1990). However, there also appears to be an interaction of soybean genotype on the plant's ability to induce resistance (Kraemer et al. 1987; Underwood et al. 2000).

Variation in plant-intrinsic factors such as genotype, leaf age/leaf position, plant structure, and plant age/growth stage can considerably influence the levels of resistance expressed against insects. In soybean, Boiça Júnior et al. (2015b) observed that leaf age/leaf position and plant age/growth stage significantly influenced the expression of constitutive resistance to the soybean specialist Anticarsia gemmatalis Hübner (Lepidoptera: Erebidae) and to the generalist Spodoptera frugiperda (J. E. Smith) (Lepidoptera: Noctuidae). Reynolds and Smith (1985) also observed differences in the levels of resistance in leaves at different plant positions of soybean genotypes to Chrysodeixis includens (Walker) (Lepidoptera: Noctuidae). Smith (1985) concluded that constitutive resistance in the soybean genotype PI 227687 is localized in leaves of the lower part of plants as the resistance levels in the upper leaves did not differ from those of the susceptible genotype Davis. Smith and Gilman (1981) reported reduced weight of $C$. includens larvae when fed on PI 227687 genotype's leaves after flowering than before flowering. Studies evaluating factors that potentially influence induced resistance in plant species are less frequent though and, therefore, merit further assessment.

For the few examples available in the literature on factors that influence induced resistance, Blackman (1974) observed that in cabbage Brassica oleracea L., Brevicoryne brassicae (Hemiptera: Aphidae) usually occurs in the younger leaves, while Myzus persicae (Hemiptera: Aphidae) is often found in the older senescent leaves. On the other hand, in potato Solanum tuberosum L., M. persicae prefers to feed on leaves from the upper part of plants of cv. Kardal. According to the authors, the cv. Kardal showed an increase in the levels of resistance to $M$. persicae aphids present in the younger leaves, which conversely decreased in the older leaves (Alvarez et al. 2006, 2007). Despite the spatial distribution of the levels of induced resistance being determined in other plant species such as tomato (Stout et al. 1994) and cottonwood (Jones et al. 1993), this is the first study to determine that induced resistance in soybean is affected by plant-intrinsic factors such as the genotype and leaf position.

Larvae of Spodoptera spp. are highlighted among the most important defoliators of soybean plants (Moscardi et al. 2012). Spodoptera cosmioides (Walker) (Lepidoptera: Noctuidae) is a highly polyphagous species considered to be increasing in population density throughout the soybean-producing regions of Brazil (Moscardi et al. 2012). In addition to the leaves, $S$. cosmioides larvae can injure the pods and seeds, which causes significant yield loss due to the direct damage in the marketable product (Santos et al. 2005; Moscardi et al. 2012). Furthermore, S. cosmioides larvae can feed twice as much soybean foliage than other co-occurring soybean lepidopteran larvae (Bueno et al. 2011). Infestations of $S$. cosmioides also raise great concern because of the reduced number of insecticides registered for its management in soybean (MAPA 2016) and inefficacy of the soybean transgenic cultivars (MON87701 $\times$ MON89788) (CTNBio 2010) expressing the Cry1Ac protein of Bacillus thuringiensis Berliner in suppressing $S$. cosmioides population densities (Santos et al. 2009; Bernardi et al. 2014).

This study investigated the effects of $S$. cosmioides herbivory, plant genotype, and leaf position/leaf age on the expression of soybean constitutive and induced resistance (antixenosis/antibiosis) to $S$. cosmioides. We also compared two methods of evaluation of the resistance effects on $S$. cosmioides biological correlates by offering either leaf discs or entire leaflets as food to larvae in laboratory bioassays. Results of this study add new information to the host plant resistance literature by demonstrating variation in soybean defense levels in function of the plant genotype and leaf position in the plant, providing insight on potential implications to plant-insect interactions in an agroecosystem.

\section{Materials and methods}

\section{Experiment conditions}

Experiments were carried out from March through June 2015 in the laboratory and greenhouse of São Paulo State University (Unesp), School of Agricultural and Veterinary Sciences, Department of Plant Protection, in Jaboticabal, state of São Paulo, Brazil. Laboratory assays were conducted under controlled conditions of temperature $\left(26 \pm 1{ }^{\circ} \mathrm{C}\right)$, relative humidity $(70 \pm 10 \%)$, and photoperiod (12L:12D h) using leaf material from soybean plants grown in the greenhouse under ambient conditions. A 
completely randomized design was used for the assays to determine the impact of plant genotype and leaf position on expression of soybean resistance. For the assays, there were a total of eight treatments arranged in a $2 \times 2 \times 2$ factorial that corresponded to the effects of genotype, herbivory, and leaf position/leaf age. This experimental design was repeated twice using two separate methods for assessing these factors, which consisted of the presented leaf material for $S$. cosmioides either from cut leaf discs or entire excised leaflets.

\section{Spodoptera cosmioides larvae}

Larvae of $S$. cosmioides used in the assays were obtained from a laboratory colony established from $\sim 200$ specimens provided by the Insect Biology Laboratory of the Superior School of Agriculture "Luiz de Queiroz", São Paulo University, Piracicaba, state of São Paulo, Brazil. Larvae were reared on an artificial diet following methodology of Greene et al. (1976), and adults were fed a $10 \%$ honey solution. Wild individuals collected from peanut plants were added to the laboratory colony to maintain the genetic diversity of the species.

\section{Soybean plants}

Soybean genotypes PI 227682 and P98Y11RR were chosen for the experiment based on their characteristics of constitutive resistance and susceptibility, respectively, to $S$. cosmioides after genotype screening performed by Boiça Júnior et al. (2015a). Plants were grown in 5-L polyethylene pots filled with soil (distrophic red latosol, Andrioli and Centurion 1999), sand, and organic bovine manure at 2:1:1 ratio. The soybean plants were kept under a greenhouse covered with No-See-Um mesh netting until use in the experiment. The plants were daily irrigated using similar amounts of water between pots and days to avoid undesired induction of water stress.

\section{Artificial infestation with Spodoptera cosmioides larvae}

In the greenhouse, plants of the soybean genotypes at vegetative stage V3-V4 ( 35 days after plant emergence) (Fher and Caviness 1977) were randomly selected and assigned to treatments. In two of eight treatments, plants of the resistant (T1) and susceptible (T2) genotypes were infested with one 5th-instar $S$. cosmioides larva in the first trifoliate from the plant base and confined in a mesh-bag cage $(10 \times 15 \mathrm{~cm})$ gently tied to a petiole with a twist tie (Fig. 1a). Larvae remained in the plants for $\sim 20 \mathrm{~h}$, in which they consumed on average $50 \%$ of the trifoliate leaf area (Underwood 1998). Larvae were starved $3 \mathrm{~h}$ prior to infestation on the plants to ensure they would consume this amount of leaf tissue. Next, both the larvae and mesh cages were removed from the plants. Control plants (without injury) had the first trifoliate from the plant base covered with mesh cages only. In two other treatments representing the resistant (T3) and susceptible (T4) genotypes, one 5thinstar $S$. cosmioides larva was infested in the second trifoliate from the plant base and confined in a mesh-bag cage (Fig. 1b), as previously described except for the leaf position. Control plants (without injury) had the second trifoliate from the plant base covered with mesh cages only.

Three days after $S$. cosmioides larvae were removed from the plants, the two outer and symmetrical leaflets of the second (T1 and $\mathrm{T} 2$ ) or first ( $\mathrm{T} 3$ and $\mathrm{T} 4)$ trifoliates from the plant base, depending on the treatment, were excised using a pair of scissors, stored in labeled plastic bags, and immediately taken to the laboratory $(<3 \mathrm{~min})$. A period of 3 days after injury was chosen based on results of Underwood (1998), who found that plants of four soybean cultivars injured by larvae of the Mexican beetle Epilachna varivestis Mulsant (Coleoptera: Coccinellidae) showed the highest levels of induced resistance at the third day after injury.

Of the two leaflets collected, one was offered to $S$. cosmioides larvae as a leaf disc and the other as an entire leaflet in two independent bioassays. Leaf discs were punched out from leaflets using a 2.5 -cm-diameter cork borer $\left(\sim 4.91 \mathrm{~cm}^{2}\right)$. Entire leaflets had a total leaf area measured by a LI-COR 3100A leaf area meter (LI-COR, Lincoln, NE, USA). Mean leaf area of the upper leaflets of the resistant genotype PI 227682 was $11.78 \mathrm{~cm}^{2}$ in injured plants and $9.66 \mathrm{~cm}^{2}$ in uninjured plants; mean leaf area of the upper leaflets of the susceptible genotype P98Y11RR was $22.72 \mathrm{~cm}^{2}$ in injured plants and $25.14 \mathrm{~cm}^{2}$ in uninjured plants; mean leaf area of the lower leaflets of PI 227682 was $10.11 \mathrm{~cm}^{2}$ in injured plants and $8.28 \mathrm{~cm}^{2}$ in uninjured plants; and mean leaf area of the lower leaflets of P98Y11RR was $26.37 \mathrm{~cm}^{2}$ in injured plants and $21.63 \mathrm{~cm}^{2}$ in uninjured plants.

\section{Evaluation of biological/nutritional indices in Spodoptera cosmioides larvae}

Leaf discs and entire leaflets from different leaf positions in injured and uninjured plants of resistant and susceptible soybean genotypes were prepared as previously described. Total leaf area was measured through an electronic leaf area meter and then food substrates were transferred into 9-cm-diameter Petri dishes lined with moistened filter paper. Thirty additional leaf samples per treatment were collected from plants, weighed in an analytical scale (Ohaus, Parsippany, NJ, USA), and kept under the same 
Fig. 1 Illustration of soybean plants subjected to herbivory by S. cosmioides larvae caged on leaflets from the lower (a) and upper trifoliates (b)
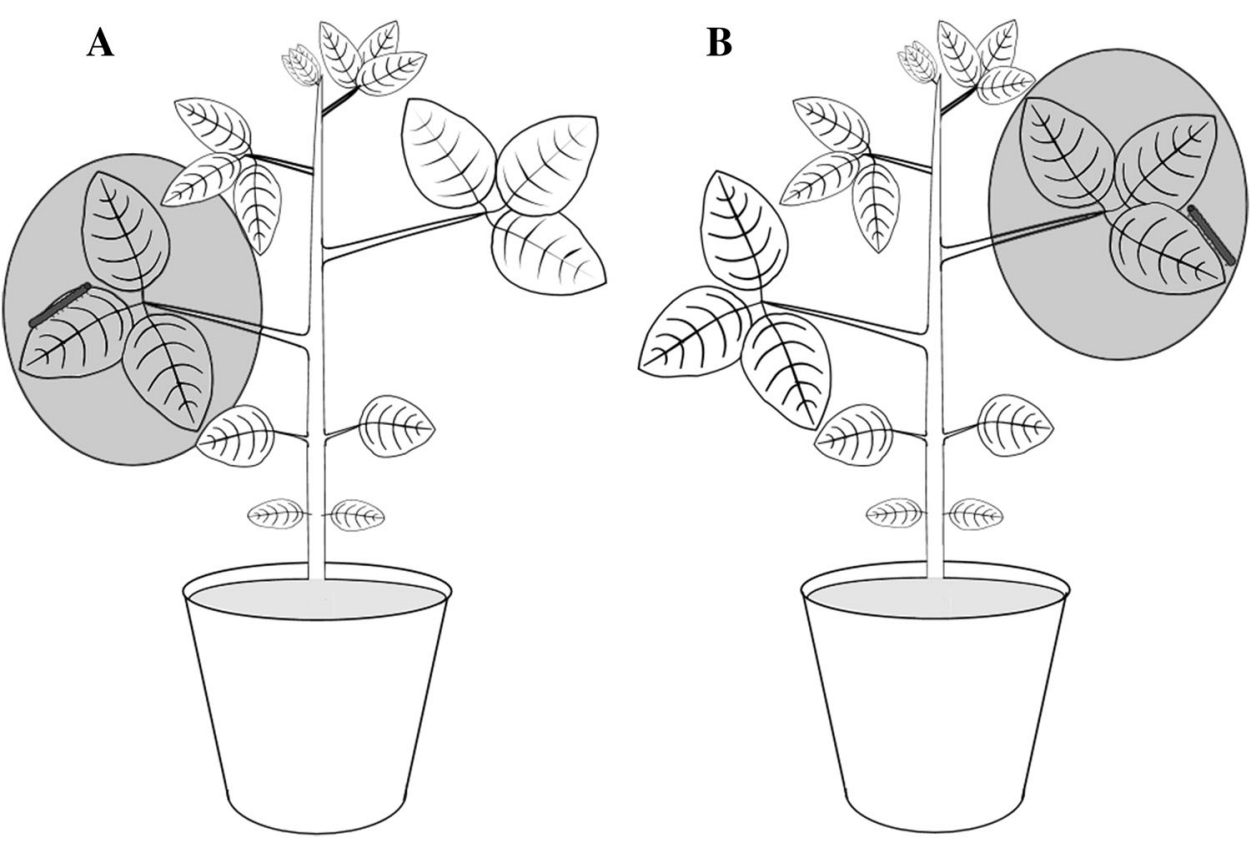

experimental conditions. The leaf samples were used as aliquots for calculating $S$. cosmioides biological/nutritional indices on a dry weight basis.

Recently molted $(<12 \mathrm{~h})$ third-instar larvae of $S$. cosmioides were collected from the laboratory colony, starved for $3 \mathrm{~h}$ to void their guts, and weighed in an analytical scale. Next, the larvae were individually transferred with the aid of a fine-tip paintbrush into Petri dishes where they remained feeding for $24 \mathrm{~h}$ in leaf-disc treatments or $48 \mathrm{~h}$ in entire-leaflet treatments. Different feeding periods were used between assays so that at least one treatment was consumed up to $80 \%$ of the leaf area. The assays were performed in a climate controlled room under $25 \pm 2{ }^{\circ} \mathrm{C}$ temperature, $70 \pm 10 \%$ relative humidity, and $12 \mathrm{~L}: 12 \mathrm{D} \mathrm{h}$ photoperiod. After the assays were ended, the larvae, the remaining food, and the entire leaflet/leaf disc aliquots were dried in an oven (Odontobrás, Ribeirão Preto, SP, Brazil) at $60{ }^{\circ} \mathrm{C}$ for $48 \mathrm{~h}$ until they reached constant weight, then they were weighed on an analytical scale. Dry weight-based values were used for calculation of the following nutritional indices: relative consumption rate (RCR), relative growth rate (RGR), and efficiency of conversion of ingested food (ECI). Calculation of indices was done following Waldbauer (1968).

\section{Statistical analysis}

Data of biological/nutritional indices were subjected to exploratory analysis to identify outlier and influent values, and checked for normality of residuals (KolmogorovSmirnov's test) and homogeneity of variances (Levene's test). When necessary, data were log-transformed to meet the assumptions of normality and homoscedasticity. Data were subjected to three-way analysis of variance (ANOVA) for the main effects of genotype $(\mathrm{G})$, herbivory $(\mathrm{H})$, leaf position $(\mathrm{L})$, and their interactions $(\mathrm{G} \times \mathrm{H}$; $\mathrm{G} \times \mathrm{L} ; \mathrm{H} \times \mathrm{L}$; and $\mathrm{G} \times \mathrm{H} \times \mathrm{L}$ ). When significance was found for ANOVA, treatment means were separated by Tukey's test $(\alpha=0.05)$. Statistical analysis was performed in SAS 9.4 software (SAS Institute 2013).

\section{Results}

\section{Leaf disc}

Our results indicated that the main effects of genotype, herbivory, and leaf position did not significantly affect the consumption and growth rates of $S$. cosmioides third-instar larvae fed soybean leaf discs, and leaf position significantly affected larvae efficiency of conversion of ingested food $\left(F_{1,56}=6.84 ; P=0.0115\right)$. Although the main effects of the investigated factors did not affect the insect consumption and growth rates, significant differences were observed for some of their interactions. The interaction between injured genotypes and the leaf position where injury took place $\left(\mathrm{G} \times \mathrm{L}: \quad F_{1}, \quad{ }_{56}=17.27 ; \quad P=0.0001 ; \quad \mathrm{H} \times \mathrm{L}:\right.$ $\left.F_{1,56}=15.63 ; P=0.0002\right)$ influenced $S$. cosmioides relative consumption rates. In addition, the genotype $\times$ leaf position and herbivory $\times$ leaf position interactions influenced the relative growth rate $\left(\mathrm{G} \times \mathrm{L}: F_{1}, 56=14.75\right.$; $\left.P=0.0003 ; \mathrm{H} \times \mathrm{L}: F_{1,56}=5.64 ; P=0.021\right)$ and efficiency of conversion of ingested food of larvae $(\mathrm{G} \times \mathrm{L}$ : 
$F_{1, \quad 56}=13.07 ; \quad P=0.0007 ; \quad \mathrm{H} \times \mathrm{L}: \quad F_{1,} \quad{ }_{56}=14.34 ;$ $P=0.0004)$ (Table 1).

Because previous herbivory in the soybean genotypes affected the relative consumption rates of $S$. cosmioides, we compared injured and uninjured resistant plants with injured and uninjured susceptible plants (Fig. 2a). Leaf consumption by larvae fed injured resistant plants was significantly lower than leaf consumption of larvae fed injured susceptible plants; however, leaf consumption was not influenced in either uninjured resistant or susceptible plants. Greater negative effect on $S$. cosmioides relative consumption rate occurred in larvae fed leaf discs from the upper part (plants injured in the lower trifoliates) of resistant plants than in larvae fed this leaf position of susceptible plants (Fig. 2b). However, the same was not observed for larvae fed leaf discs from the lower trifoliate of soybean plants. Larvae consumption rate in susceptible plants was significantly greater in the upper than in the lower trifoliates, whereas in resistant plants there was a slight numerical reduction of larvae consumption rate in leaf discs from the upper trifoliate, but without significant difference between leaf positions. For larvae fed on leaf positions from injured and uninjured plants (Fig. 2c), larvae relative consumption rate was reduced in leaf discs from the lower trifoliate of uninjured plants, but there was no significant difference between the upper and lower trifoliates of injured plants.

Significant effects on the relative growth rates of $S$. cosmioides larvae fed leaves from the upper and lower parts of resistant and susceptible genotypes were observed. Larvae experienced greater growth reductions when fed leaf discs from the upper trifoliate than larvae fed leaf discs from the lower trifoliate of injured plants. On the other hand, there were no significant effects on larvae that were fed on different leaf positions of uninjured plants. Interestingly, the relative growth rate was numerically higher in larvae fed leaves from the upper trifoliate in uninjured plants, but when larvae were fed leaves from the same leaf position in injured plants there were significant reductions in the relative growth rates (Fig. 2d). Regarding the genotype $\times$ leaf position interactive effects (Fig. 2e), $S$. cosmioides larvae showed greater growth reductions when fed leaf discs from the upper trifoliate of resistant soybean than larvae fed discs from the lower trifoliate; conversely, larvae fed leaf discs from the upper trifoliate of susceptible plants did not have growth affected and was similar to larvae fed leaf discs from the lower trifoliate. In synthesis, negative effects on $S$. cosmioides relative growth rates were observed in the upper trifoliate of injured resistant plants, but were absent in injured susceptible plants (Fig. 2e).

The efficiency of conversion of ingested food in $S$. cosmioides larvae was assessed in both leaf positions of injured and uninjured soybean genotypes. Greater negative effect occurred in larvae fed on the upper trifoliate of injured plants, which provided the lowest percentage of efficiency of conversion of ingested food, whereas in uninjured plants larvae exhibited the same efficiency when fed either trifoliate (Fig. 2f). When the genotypes were
Table 1 Summary of the ANOVA for the effects of genotype, herbivory, and leaf position on biological correlates (RCR, RGR, and ECI) of $S$. cosmioides larvae fed leaf discs or entire leaflets of soybean

\begin{tabular}{|c|c|c|c|c|c|c|}
\hline \multirow[t]{2}{*}{ Effects } & \multicolumn{2}{|l|}{ RCR } & \multicolumn{2}{|l|}{ RGR } & \multicolumn{2}{|l|}{ ECI } \\
\hline & $F$ & $P$ & $F$ & $P$ & $F$ & $P$ \\
\hline \multicolumn{7}{|l|}{ Leaf disc } \\
\hline Genotype (G) & 2.51 & 0.1189 & 2.19 & 0.1447 & 0.39 & 0.5331 \\
\hline Herbivory (H) & 0.49 & 0.4878 & 0 & 0.9547 & 0.14 & 0.7058 \\
\hline Leaf position (L) & 1.58 & 0.2136 & 0.10 & 0.7499 & $6.84 *$ & 0.0115 \\
\hline $\mathrm{G} \times \mathrm{H}$ & $6.09 *$ & 0.0166 & 0.06 & 0.8034 & 0.04 & 0.8433 \\
\hline $\mathrm{G} \times \mathrm{L}$ & $17.27 * * *$ & 0.0001 & $14.75 * *$ & 0.0003 & $13.07 * *$ & 0.0007 \\
\hline $\mathrm{H} \times \mathrm{L}$ & $15.63 * *$ & 0.0002 & $5.64 *$ & 0.021 & $14.34 * *$ & 0.0004 \\
\hline $\mathrm{G} \times \mathrm{H} \times \mathrm{L}$ & 0.02 & 0.8807 & 0.87 & 0.3539 & 1.40 & 0.2417 \\
\hline \multicolumn{7}{|l|}{ Entire leaflet } \\
\hline Genotype (G) & $7.36 * *$ & 0.0088 & $38.18 * * *$ & $<0.0001$ & $25.13 * * *$ & 0.0001 \\
\hline Herbivory (H) & 3.53 & 0.0654 & 1.23 & 0.2728 & 1.92 & 0.1718 \\
\hline Leaf position (L) & 0.23 & 0.6333 & 0.05 & 0.8214 & $4.58^{*}$ & 0.0368 \\
\hline $\mathrm{G} \times \mathrm{H}$ & $5.31 *$ & 0.025 & 1.75 & 0.1918 & 0.59 & 0.4462 \\
\hline $\mathrm{G} \times \mathrm{L}$ & $6.48^{*}$ & 0.0137 & 0.85 & 0.3611 & 1.21 & 0.2768 \\
\hline $\mathrm{H} \times \mathrm{L}$ & $7.39 * *$ & 0.0087 & 2.44 & 0.1241 & 0.00 & 0.9675 \\
\hline $\mathrm{G} \times \mathrm{H} \times \mathrm{L}$ & 2.53 & 0.1172 & 1.82 & 0.1831 & 0.53 & 0.4701 \\
\hline
\end{tabular}

$R C R$ relative consumption rate, $R G R$ relative growth rate, $E C I$ efficiency of conversion of ingested food $* P<0.05 ; * * P<0.01 ; * * * P<0.0001$ 

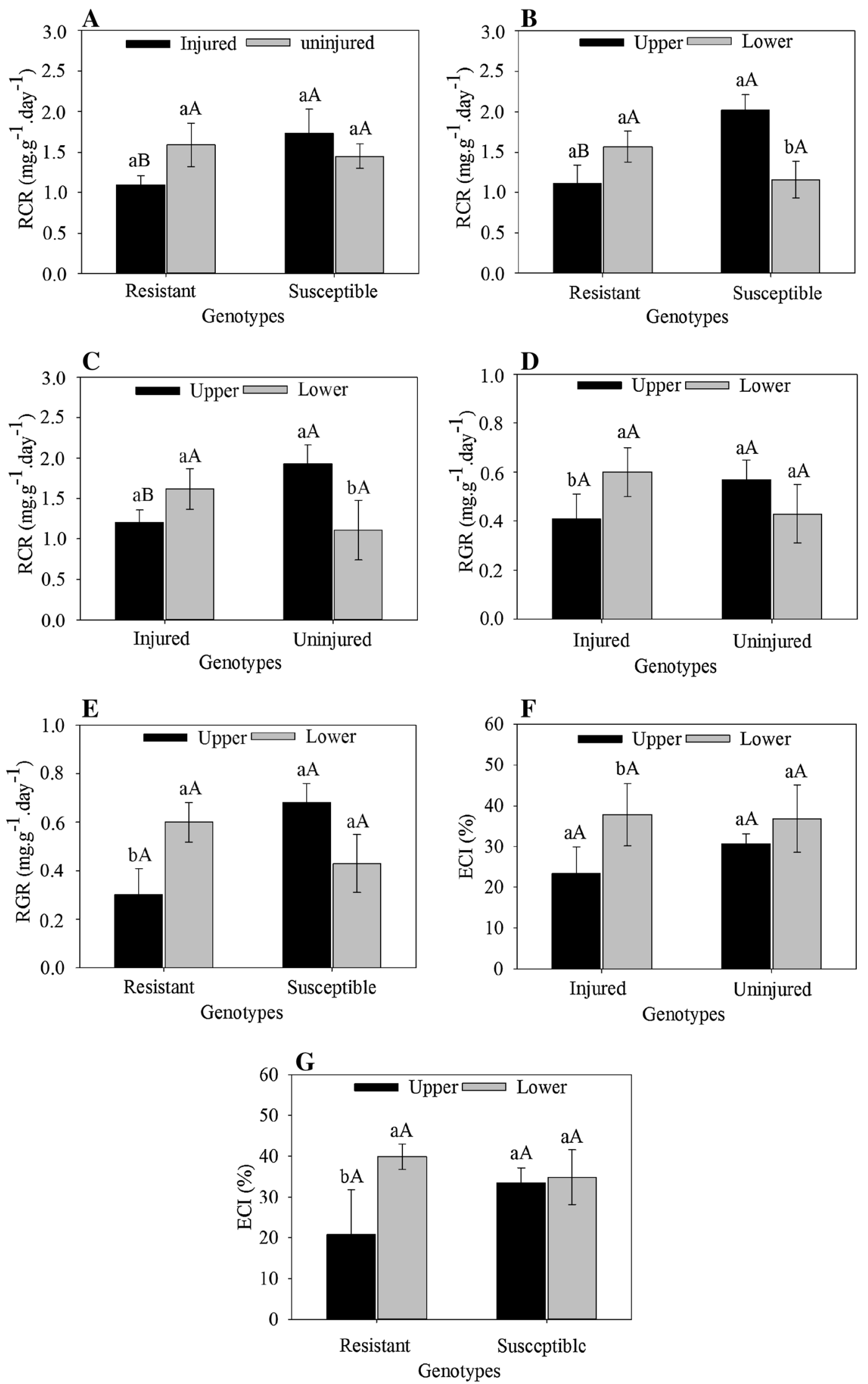
४Fig. 2 Relative consumption rate, relative growth rate, and efficiency of conversion of ingested food of $S$. cosmioides larvae fed leaf discs from the upper and lower trifoliates of injured and uninjured soybean plants. Bars topped with different lowercase letters indicate significant difference between either injured or uninjured plants and leaf positions; bars topped with different uppercase letters indicate significant difference between resistant and susceptible genotypes and injured and uninjured plants $(P<0.05)$

analyzed separately (Fig. 2g), the efficiency of conversion of ingested food was not affected in larvae fed on leaf positions in the susceptible soybean plants, but larvae fed on the upper trifoliate of resistant plants were highly affected (20\% lower efficiency).

\section{Entire leaflet}

The results obtained with entire leaflets indicated that soybean genotype significantly affected the consumption $\left(F_{1}, \quad 56=7.36 ; \quad P=0.0088\right)$ and growth rates $\left(F_{1,56}=38.18 ; P=0.0001\right)$, as well as the efficiency of conversion of ingested food $\left(F_{1,56}=25.13 ; P=0.0001\right)$ of $S$. cosmioides third-instar larvae. Leaf position only affected larvae efficiency of conversion of ingested food $\left(F_{1,56}=4.58 ; P=0.0368\right)$ and herbivory did not influence any nutritional parameter of $S$. cosmioides. Some interactive effects on the insect nutritional indices were observed between investigated factors (Table 1).

Because the effects of the genotype $\times$ herbivory interaction significantly influenced the consumption and growth rates and efficiency of conversion of ingested food of $S$. cosmioides, we compared injured and uninjured resistant plants with injured and uninjured susceptible plants (Fig. 3). Larvae leaf consumption was lower in entire leaflets from injured resistant plants than uninjured resistant plants (Fig. 3a), whereas larvae fed leaflets from susceptible soybean showed similar consumption rates between injured and uninjured plants. Significant differences were not found in the consumption rates of $S$. cosmioides larvae fed foliage between the upper and lower trifoliates of either injured or uninjured plants (Fig. 3b). Lower consumption rates were observed in larvae fed leaflets from the upper trifoliate of injured plants than larvae fed the same leaf position of uninjured plants. $S$. cosmioides larvae exhibited lower consumption rates when fed leaflets from the upper trifoliate of resistant soybean plants than larvae fed leaflets from the same trifoliate of susceptible plants (Fig. 3c). Larvae that consumed foliage from the lower trifoliate had similar consumption rates in resistant and susceptible plants. In both soybean genotypes, there was no significant difference in leaf consumption between larvae fed leaflets from the upper and lower trifoliates.
The significant effects on the growth rates (Fig. 3d) and efficiency of conversion of ingested food (Fig. 3e, f) in larvae fed soybean genotypes indicated that $S$. cosmioides had reduced growth and lower efficiency of conversion of food to body mass when fed leaflets from the resistant genotype relative to the susceptible genotype. Moreover, the efficiency of conversion of ingested food was lower in larvae fed on the upper trifoliate relative to the lower trifoliate of soybean genotypes (Fig. 3g).

Overall, it was noted that genotype PI 227687 expressed induced resistance after $S$. cosmioides herbivory when leaf discs were offered as food to larvae, and the negative induced effects occurred systemically in the upper trifoliate of plants when injury took place in the lower trifoliate; such effect was not observed in the susceptible genotype Pioneer 98Y11. Food offered to larvae as entire leaflet did not allow a clear distinction in the levels of induced resistance between soybean genotypes and mostly evinced expression of constitutive resistance in the genotype PI 227687.

\section{Discussion}

This study demonstrates that the soybean plant-intrinsic factors genotype (resistant or susceptible) and leaf position (upper or lower trifoliates) significantly interact with $S$. cosmioides herbivory and affect the levels of soybean resistance (antixenosis/antibiosis) to conspecific larvae feeding and growth. It was also noted that the use of different methods of offering food to larvae, as leaf disc or entire leaflet, can result in slight variation in the insect biological responses obtained. These results contribute to understanding the allocation of soybean constitutive and induced defenses toward the attack of a highly polyphagous defoliating larvae and optimization of a methodology to research soybean induced resistance. Finally, we discuss the results by pointing out potential implications that these findings could exert on plant-insect interactions in a soybean agroecosystem.

We determined that leaves from injured resistant soybean considerably affects $S$. cosmioides larvae consumption rates when compared to larvae fed foliage from uninjured resistant plants. Conversely, consumption rates are not affected in injured susceptible soybean. Larvae that developed on foliage from uninjured plants of both genotypes exhibited similar consumption rates. Therefore, we can infer that soybean plants bearing constitutive resistant traits also express induced resistance to $S$. cosmioides when injured by conspecific larvae, but interestingly, the same response was not observed in constitutively susceptible soybean plants. 

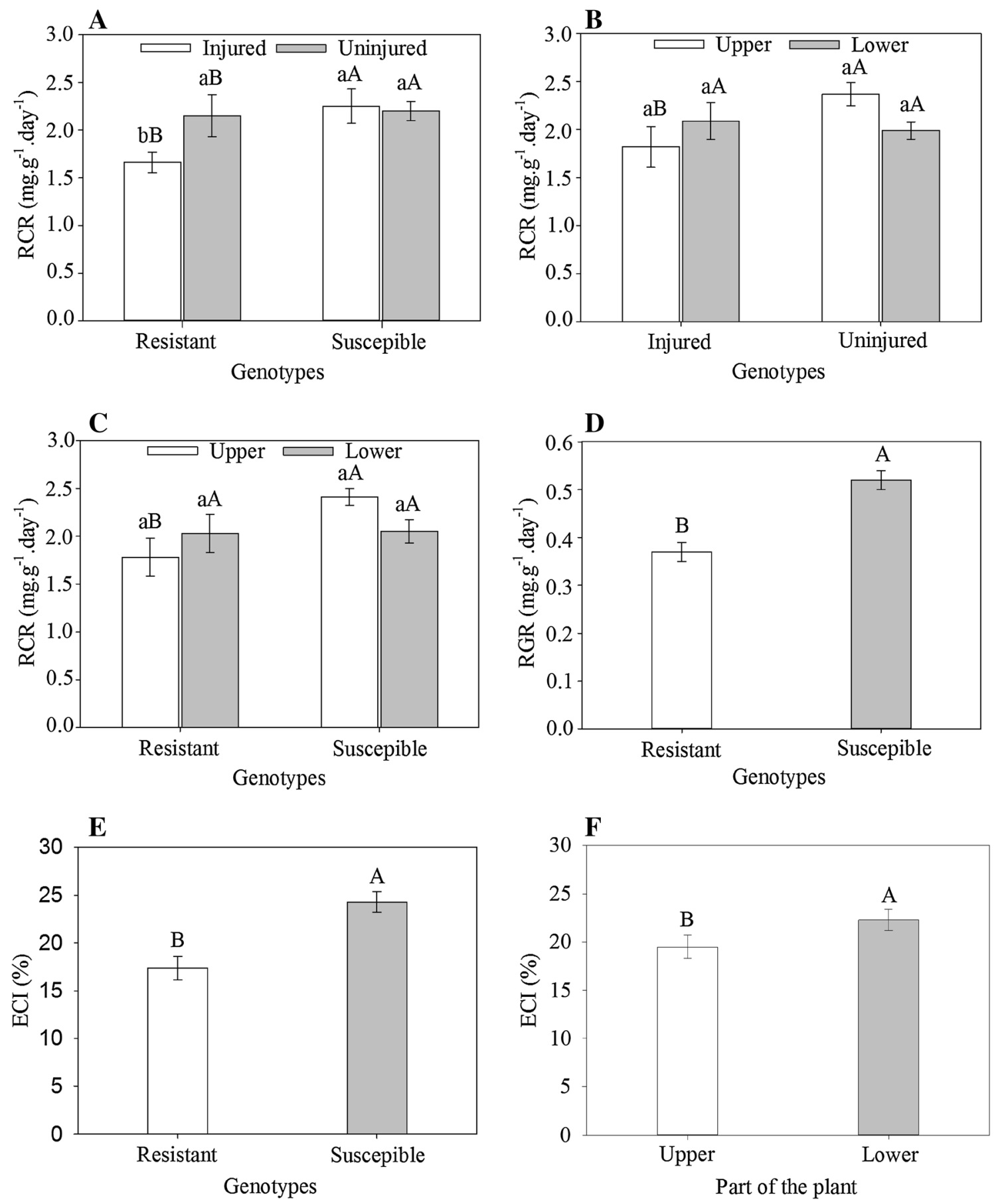

Fig. 3 Relative consumption rate, relative growth rate, and efficiency of conversion of ingested food of $S$. cosmioides larvae fed entire leaflets from the upper and lower trifoliates of injured and uninjured soybean plants. Bars topped with different lowercase letters indicate

Studies have reported the occurrence of induced resistance in soybean plants injured by arthropod species, notably C. includens, E. varivestis (Lin and Kogan 1990), Tetranychus urticae Koch (Acari: Tetranychidae) (Brown et al. 1991), H. zea (Bi et al. 1994; Felton et al. 1994), and A. gemmatalis (Fortunato et al. 2007). In

significant difference between either injured or uninjured plants and leaf positions; bars topped with different uppercase letters indicate significant difference between resistant and susceptible genotypes and injured and uninjured plants $(P<0.05)$

some cases, constitutively susceptible plants induced resistance after herbivory. For instance, Underwood (1998) evaluating four soybean genotypes constitutively susceptible to $E$. varivestis observed that all genotypes induced resistance after the insect herbivory. Two soybean genotypes constitutively susceptible to Cerotoma 
trifurcata (Foster) (Coloptera: Chrysomelidae) expressed induced resistance to adult beetles, and did not differ from the resistant genotype (Srinivas and Danielson 2001). Despite there being reports on the occurrence of trade-offs between constitutive and induced resistance (Stamp 2003), this is still an issue of debate. According to Underwood et al. (2000), there is no positive correlation between soybean constitutive and induced resistance to $E$. varivestis, differing from the findings obtained in our study whereby only the genotype with constitutive resistance enhanced the levels of resistance after $S$. cosmioides herbivory. Divergent results pointing to positive or negative correlations between expression of constitutive and induced resistance, or even without any significant correlation, were previously reported (Karban and Baldwin 1997).

Leaf position influenced S. cosmioides larvae consumption and growth rates in both soybean genotypes. Larvae showed greater leaf consumption and weight gain in the upper trifoliate of injured and uninjured susceptible soybean relative to larvae fed the lower trifoliates. According to Smith (2005), younger leaves are usually preferred by arthropods for feeding than older leaves. Different plant parts can greatly differ regarding the nutritional (Waldbauer and Friedman 1991; Behmer 2009; Souza 2014) and allelochemical composition (Rose et al. 1988; Souza 2014), which influence feeding preference and development of herbivorous arthropods. In soybean plants, younger and softer leaves that are closer to the plant apex were preferred by $H$. zea and T. urticae than leaves from lower plant strata (McWilliams and Beland 1977; Rodriguez et al. 1983). Fully expanded leaves from the two trifoliates closer to the plant apex of a resistant soybean genotype were less resistant to $C$. includens than were the trifoliates from the lower part of plants (Reynolds and Smith 1985). Nault et al. (1992) confirmed this trend in leaves of soybean genotypes resistant to $H$. zea and $A$. gemmatalis.

Injury inflicted by $S$. cosmioides larvae in the lower trifoliate of PI 227687 plants later caused an induced defensive response to larvae fed the upper trifoliate, leading to lower rates of larval consumption and growth, and lower efficiency of conversion of ingested food to body mass. On the other hand, when PI 227687 plants were injured in the upper trifoliate, larvae fed excised leaves from the lower trifoliate showed rates of leaf consumption, growth, and efficiency of conversion of ingested food similar to larvae fed uninjured plants. This brings up two interesting phenomena: only the PI 227687 genotype possesses the ability to induce resistance to $S$. cosmioides herbivory, and defenses were shunted to the younger leaf that was closer to the plant apex, which was initially more suitable to larvae feeding and growth.
Induced defenses are first produced at the site of injury and near to tissues injured by herbivorous arthropods (local response), and thereafter induced responses may occur in distant plant tissues that were not directly injured (systemic response) (Howe and Schaller 2008; Hammerschmidt 2014). Among the induced responses to herbivory are the expression of genes encoding for the synthesis of alkaloids, terpenes, phenolics, and other defensive compounds, as well as genes related to injury repair, including callose synthases and peroxidases (Kant and Williams 2013). Insect herbivory also induces the accumulation of proteins and other compounds with anti-digestive properties, such as proteinase inhibitors that interfere with insect gut proteolytic enzymes (Kant and Williams 2013). Several works have reported that increased activities of peroxidase and polyphenol oxidase are correlated with plant induced resistance to lepidopteran larvae (Felton et al. 1989, 1992, 1994; Mahanil et al. 2008; Zhu-Salzman et al. 2008; Souza 2014). These enzymes are responsible for catalyzing the oxidation of phenolics to quinones, which are toxic compounds to microorganisms and insects (Stout et al. 1994). To investigate this question, we will conduct a follow-up study to quantify concentrations of selected candidate chemical compounds that may be linked with soybean induced resistance, including oxidative enzymes, proteinase inhibitors, and flavonoids between the upper and lower soybean trifoliates. Molecular analysis on expression of selected defense-related genes in the soybean genotypes here evaluated can give us further insight on possible underlying mechanisms of induced resistance to insect herbivory.

Food offered as a leaf disc allowed for better discrimination of soybean induced resistance levels to $S$. cosmioides herbivory, contrary to food offered as an entire leaflet whose induced response was less pronounced; using entire leaflets in bioassays, we were unable to observe significant effects of herbivory on some insect biological parameters that were provided by the use of leaf discs (e.g. rates of $S$. cosmioides larval growth and efficiency of conversion of ingested food). Secondary metabolites in plants are often stored separately from the cell cytoplasm (e.g. in vacuoles, cell wall, epidermis cells, etc.) as soon as they are synthesized by metabolic processes throughout plant development (Panda and Kush 1995). Upon preparation of leaf discs with a cork borer, rupture of cells or organelles storing the secondary metabolites probably occurred, resulting in their release and thereby greater exposure to insects during the course of the bioassay (Boiça Júnior et al. 2015b). Effects were less pronounced in entire leaflets than leaf discs probably because larvae must first disrupt the structures storing defensive secondary compounds prior to being in contact with them. Therefore, the best results obtained with leaf discs in demonstrating 
soybean induced resistance were likely due to greater and more rapid exposure of $S$. cosmioides larvae to secondary metabolites and volatile organic compounds, especially in the case of the resistant genotype PI 227687.

Both use of leaf discs and entire leaflets are often employed in host plant resistance studies (Smith 2005), but varying responses can occur between methods depending on investigated species of plants and insects. Huang et al. (2003) reported that higher levels of constitutive resistance in lettuce genotypes to Diabrotica balteata LeConte (Coleoptera: Chrysomelidae) were obtained using intact leaves than leaves excised from plants. In addition, when the resistant genotype was offered to insects as a leaf disc, resistance was not expressed (Huang et al. 2003). Boiça Júnior et al. (2015b) evaluating the feeding preference of $A$. gemmatalis larvae in soybean resistant and susceptible genotypes concluded that greater differences in leaf consumption between genotypes were found using leaf discs than entire leaflets. Although the evaluation of $S$. cosmioides biological parameters in larvae infested on plants rather than in Petri dishes could provide a more realistic scenario, other works also showed soybean induced resistance responses in bioassays using cut leaf discs (Underwood 1998) and excised entire leaflets (Lin and Kogan 1990; Bi et al. 1994). In addition, Kogan and Fischer (1991) reported that leaf excision by the petiole was the least effective way to induce resistance in soybean. The varying responses of plant resistance reported in the literature with the use of leaf discs and entire leaflets stress the importance of knowing the factors that influence expression of resistance in diverse plant-insect systems before the conduction of genotype screening.

The results found for soybean induced resistance to $S$. cosmioides herbivory are in agreement with the optimal defense theory (McKey 1979). This theory posits that defenses are costly for plants, and younger leaves are more defended than older leaves because of their distinct importance for plant development and insect attack probability. Results obtained in other studies also corroborate the optimal defense theory assumptions (Stamp 2003). In Brassica juncea plants, allocation of glucosinolate-myrosinase defenses in cotyledons follows the optimal defense model regarding the defense investment across plant tissues in function of the fitness value for the plants (Wallace and Eigenbrode 2002); during periods in which the cotyledons were essential for the plant growth, activity of myrosinase enzymes and concentrations of glucosinolates were increased, whereas the defense levels lowered as the importance of the cotyledons decreased. Extrafloral nectar production rates (Wackers and Bonifay 2004; Radhika et al. 2008; Holland et al. 2009) and trichome densities (Traw and Feeny 2008) were also shown to be in agreement with the optimal defense theory. Other examples are volatile organic compounds that are emitted at higher concentrations from soybean younger leaves than from older leaves (Rostás and Eggert 2008). Therefore, there is evidence that induction of chemical defenses is correlated with plant tissue value (Zangerl and Rutledge 1996; Strauss et al. 2004). The fact that soybean plants can show resistance induction with varying levels depending on the plant tissue makes this plant species an ideal model for investigating patterns of defense allocation against specialist and generalist insects.

From an ecological perspective, herbivory-induced effects in soybean younger leaves suggest that $S$. cosmioides larvae within-plant distribution could be altered in an agroecosystem after insect attack. Induction of resistance could also affect population dynamics of other species of arthropods sharing the same or different niches, with potential effects in insect competition. There is evidence that, in addition to differences in amounts of injury, resistance induction triggered by insect attack influences insect performance and population dynamics, such as birth, growth, and survival (Karban and Baldwin 1997; Abbott et al. 2008). Limitation of feeding resources overall results in herbivore dispersion, leading to cospecific repulsion without induced mechanisms, whereas in cases of resistance induction herbivores show aggregation behavior (Underwood et al. 2005; Anderson et al. 2015). Induction of resistance should be further investigated first in the greenhouse and then in field conditions with the aim of elucidating its role on within-plant distribution of insect species with similar and distinct niches. Consequently, plant physiological alterations and reallocation of defenses after insect attack could change patterns of insect feeding preference within the plant, possibly affecting intraspecific and interspecific competition, which merits a deeper investigation.

This work demonstrates that soybean defense induction to defoliating S. cosmioides larvae is dependent on both the plant genotype and leaf position. When assessing genotypes for constitutive and induced resistance, the use of different methods of offering food to insects in bioassays can yield slight variations in the insect biological responses, so that methodology optimization can benefit genotype-screening assays for making them more precise and practical. The results found in our study suggest that effects of plant-intrinsic factors on insects should be taken into account when categorizing a plant genotype for insect resistance, given the plant phenotypic plasticity to herbivory. Finally, we emphasize the importance that herbivory-induced responses may exert on the regulation of pest populations in a soybean agroecosystem, and encourage future research at investigating the effects of soybean induced resistance on within-plant distribution and competition of insects that share similar and distinct niches. 
Acknowledgments We thank Coordenação de Aperfeiçoamento de Pessoal de Nivel Superior (Coordination for the Improvement of Higher Education Personnel, CAPES, Brazil) for funding this research.

\section{References}

Abbott KC, Morris WF, Gross K (2008) Simultaneous effects of food limitation and inducible resistance on herbivore population dynamics. Theor Popul Biol 73:63-78

Agrawal AA (1998) Induced responses to herbivory and increased plant performance. Science 279:1201-1202

Alvarez AE, Tjallingii WF, Garzo E, Vleeshouwers V, Dicke M, Vosman B (2006) Location of resistance factors in the leaves of potato and wild tuber-bearing Solanum species to the aphid Myzus persicae. Entomol Exp Appl 121:145-157

Alvarez AE, Garzo E, Verbeek M, Vosman B, Dicke M, Tjallingii WF (2007) Infection of potato plants with potato leafroll virus changes attraction and feeding behavior of Myzus persicae. Entomol Exp Appl 125:135-144

Anderson KE, Inouye BD, Underwood N (2015) Can inducible resistance in plants cause herbivore aggregations? Spatial patterns in an inducible plant/herbivore model. Ecology 96:2758-2770

Andrioli I, Centurion JF (1999) Levantamento detalhado dos solos da Faculdade de Ciências Agrárias e Veterinárias de Jaboticabal. In: Congresso brasileiro de ciência do solo. Anais... Sociedade Brasileira de Ciência do Solo, Brasília, pp. 1-4

Behmer S (2009) Insect herbivore nutrient regulation. Annu Rev Entomol 54:165-187

Bernardi O, Sorgatto RJ, Barbosa AD, Fomingues FA, Dourado PM, Carvalho RA, Martinelli S, Head GP, Omoto C (2014) Low susceptibility of Spodoptera cosmioides, Spodoptera eridania, and Spodoptera frugiperda (Lepidoptera: Noctuidae) to genetically-modified soybean expressing Cry1Ac protein. Crop Protection 58:33-40

Bi JL, Felton GW (1995) Foliar oxidative stress and insect herbivory-primary compounds, secondary metabolites, and reactive oxygen species as components of induced resistance. J Chem Ecol 21:1511-1530

Bi JL, Felton GW, Mueller AJ (1994) Induced resistance in soybean to Helicoverpa zea: role of plant protein quality. J Chem Ecol 20:183-198

Blackman R (1974) Aphids. London and Aylesbury, Ginn \& Company Limited

Boiça Júnior AL, Bottega DB, Souza BHS, Rodrigues NEL, Michelin V (2015a) Determinação dos tipos de resistência a Spodoptera cosmioides (Walker) (Lepidoptera: Noctuidae) em genótipos de soja. Semina 36:607-618

Boiça Júnior AL, Souza BHS, Costa EN, Ribeiro ZA, Stout MJ (2015b) Factors influencing expression of antixenosis in soybean to Anticarsia gemmatalis and Spodoptera frugiperda (Lepidoptera: Noctuidae). J Econ Entomol 108:317-325

Brown GC, Nurdin F, Rodriguez JG, Hildebrand DF (1991) Inducible resistance of soybean (var 'Williams') to twospotted spider mite (Tetranychus urticae Koch). J Kansas Entomol Soc 64:388-393

Bueno RCOF, Bueno AF, Moscardi F, Parra JRP, Hoffmann-Campo CB (2011) Lepidopteran larvae consumption of soybean foliage: basis for developing multiple-species economic thresholds for pest management decisions. Pest Manag Sci 67:170-174

Coley PD, Barone JA (1996) Herbivory and plant defenses in tropical forests. Annu Rev Ecol Syst 27:305-335

CTNBio (Comissão Técnica Nacional de Biossegurança) (2010) Technical Opinion No. 2542/2010-Commercial Release of
Genetically Modified Insect-resistant and Herbicide-tolerant Soy Containing Genetically Modified Events MON 87701 and MON 89788. http://www.ctnbio.gov.br/index.php/content/view/ 15558.html. Accessed 15 February 2016

El-Wakeil NE, Volkmar C, Sallam AA (2010) Jasmonic acid induces resistance to economically important insect pests in winter wheat. Pest Manag Sci 66:549-554

Felton GW, Broadway RM, Duffey SS (1989) Inactivation of proteinase inhibitor activity by plant-derived quinones: complications for host-plant resistance against noctuid herbivores. J Insect Physiol 35:981-990

Felton GW, Donato KK, Broadway RM, Duffey SS (1992) Impact of oxidized plant phenolics on the nutritional quality of dietary protein to a noctuid herbivore. J Insect Physiol 38:277-285

Felton GW, Summers CB, Mueller AJ (1994) Oxidative responses in soybean foliage to herbivory by bean leaf beetle and threecornered alfalfa hopper. J Chem Ecol 20:639-649

Fher WR, Caviness CE (1977) Stages of soybean development. Iowa State University of Science and Technology, Ames

Fortunato FS, Oliveira MGA, Brumano MHN, Silva CHO, Guedes RNC, Moreira MA (2007) Lipoxygenase-induced defense of soybean varieties to the attack of the velvetbean caterpillar (Anticarsia gemmatalis Hübner). J Pest Sci 80:241-247

Greene GL, Leppla NC, Dickerson WA (1976) Velvet bean caterpillar: a rearing procedure and artificial medium. J Econ Entomol 69:487-488

Hamm JC, Stout MJ, Riggio RM (2010) Herbivore- and elicitorinduced resistance in rice to the rice water weevil (Lissorhoptrus oryzophilus Kuschel) in the laboratory and field. J Chem Ecol 36:191-199

Hammerschmidt R (2014) Introduction: Definitions and Some History. In: Walters DR, Newton AC, Lyon GD (eds) Induced Resistance for Plant Defense: A Sustainable Approach to Crop Protection, 2nd edn. John Wiley \& Sons, New Jersey, pp 1-10

Hoffmann-Campo CB, Harborne JB, McAferry AR (2001) Preingestive and post-ingestive effects of soya bean extracts and rutin on Trichoplusia ni growth. Entomol Exp Appl 98:181-194

Holland JN, Chamberlain SA, Horn KC (2009) Optimal defence theory predicts investment in extrafloral nectar resources in an ant-plant mutualism. J Ecol 9:89-96

Howe GA, Schaller A (2008) Direct Defenses in Plants and Their Induction by Wounding and Insect Herbivores. In: SCHALLER A (ed). Induced plant resistance to herbivory. Springer, Heidelberg, pp 7-30

Huang J, Nuessly GS, McAuslane HJ, Nagata RT (2003) Effects of screening methods on expression of romaine lettuce resistance to adult banded cucumber beetle, Diabrotica balteata (Coleoptera: Chrysomelidae). Flor Entomol 86:194-198

Jones CG, Hopper RF, Coleman JS, Krischik VA (1993) Control of systemically induced herbivore resistance by plant vascular architecture. Oecologia 93:452-456

Kant MR, Williams M (2013) Plants and arthropods: friends or foes? Plant Cell. doi:10.1105/tpc.111.tt0811

Karban R, Baldwin IT (1997) Induced response to herbivory. University of Chicago Press, Chicago

Kogan M, Fischer DC (1991) Inducible defenses in soybean against herbivorous insects. In: Raupp MJ, Tallamy DW (eds) Phytochemical induction by herbivores. Wiley, New York, pp 337-347

Kraemer ME, Rngappa M, Gade W, Benepal PS (1987) Induction of trypsin inhibitors in soybean leaves by Mexican bean beetle (Coleoptera: Coccinellidae) defoliation. J Econ Entomol 80:237-241

Lin H, Kogan M (1990) Influence of induced resistance in soybean on the development and nutrition of the soybean looper and the Mexican bean beetle. Entomol Exp Appl 55:131-138 
Lin H, Kogan M, Fischer D (1990) Induced resistance in soybean to the Mexican bean beetle (Coleoptera: Coccinellidae): comparison of inducing factors. Environ Entomol 19:1852-1857

Mahanil S, Attajarusit J, Stout MJ, Thipyapong P (2008) Overexpression of tomato polyphenol oxidase increases resistance to common cutworm. Plant Sci 174:456-466

McKey D (1979) The distribution of secondary metabolites within plants. In: Rosenthal GA, Jansen DH (eds) Herbivores: their interaction with secondary plant metabolites. Academic Press, New York

McWilliams JM, Beland GL (1977) Bollworm: effect of soybean leaf age and pod maturity on development in the laboratory. Ann Entomol Soc Am 70:214-216

MAPA. Ministério da Agricultura, Pecuária e Abastecimento (2016) AGROFIT: sistema de agrotóxicos fitossanitários. MAPA, Brasília. http://agrofit.agricultura.gov.br/agrofit_cons/principal_ agrofit_cons. Accessed 16 Apr 2016

Moscardi F, Bueno AF, Sosa-Gómez DR, Roggia S, HoffmannCampo CB, Pomari AF, Corso IC, Yano SAC (2012) Artrópodes que atacam as folhas da soja. In: Hoffmann-Campo CB, CorrêaFerreira BS, Moscardi F (eds) Soja: manejo integrado de insetos e outros artrópodes praga. Embrapa, Brasília, pp 213-334

Nault BA, All JN, Boerma HR (1992) Resistance in vegetative and reproductive stages of a soybean breeding line to three defoliating pests (Lepidoptera: Noctuidae). J Econ Entomol 85:1507-1515

Panda N, Kush GS (1995) Host plant resistance to insects. CAB/ International Rice Research Institute, Wallingford

Piubelli GC, Hoffmann-Campo CB, Moscardi F, Miyakubo SH, Oliveira MCN (2005) Are chemical compounds important for soybean resistance to Anticarsia gemmatalis? J Chem Ecol 31:1509-1525

Radhika V, Kost C, Bartram S, Heil M, Boland W (2008) Testing the optimal defence hypothesis for two indirect defences: extrafloral nectar and volatile organic compounds. Planta 228:449-457

Reynolds GW, Smith CM (1985) Effects of leaf position, leaf wounding, and plant age of two soybean genotypes on soybean looper (Lepidoptera: Noctuidae) growth. Environ Entomol 14:475-478

Rodriguez JG, Reicosky DA, Patterson CG (1983) Soybean and mite interactions: effects of genotype and plant growth stage. J Kansas Entomol Soc 56(320):326

Rose RL, Sparks TC, Smith CM (1988) Insecticide toxicity to larvae of Pseudoplusia includens (Walker) and Anticarsia gemmatalis (Hubner) (Lepidoptera) as influenced by feeding on resistant soybean (PI227687) leaves and coumestrol. J Econ Entomol 81:1288-1294

Rostás M, Eggert K (2008) Ontogenetic and spatio-temporal patterns of induced volatiles in Glycine max in light of the optimal defence hypothesis. Chemecology 18:29-38

Santos KB, Meneguim AM, Neves PMOJ (2005) Biologia de Spodoptera eridania (Cramer) (Lepidoptera: Noctuidae) em diferentes hospedeiros. Neotrop Entomol 34:903-910

Santos KB, Neves PJ, Meneguim AM, Santos RB, Santos WJ, Villas Boas G, Dumas V, Martins E, Praça LB, Queiroz P, Berry C, Monnerat R (2009) Selection and characterization of the Bacillus thuringiensis strains toxic to Spodoptera eridania (Cramer), Spodoptera cosmiodes (Walker) and Spodoptera frugiperda (Smith) (Lepidoptera: Noctuidae). Biol Control 50:157-163

SAS Institute (2013) SAS/STATVR 9.4 User's Guide. SAS Institute, Cary
Smith CM (1985) Expression, mechanisms and chemistry of resistance in soybean, Glycine max L. (Merr.) to the soybean looper, Pseudoplusia includes (Walker). Int J Trop Insect Sci 6:243-248

Smith CM (2005) Plant resistance to arthropods: molecular and conventional approaches. Springer, Dordrecht

Smith CM, Gilman DF (1981) Comparative resistance of multiple insect-resistant soybean genotypes to the soybean looper. J Econ Entomol 74:400-403

Souza BHS (2014) Fatores e mecanismos que influenciam a resistência em soja a Anticarsia gemmatalis Hübner e Spodoptera frugiperda (J. E. Smith). Thesis, School of Agriculture and Veterinary Sciences, São Paulo State University

Srinivas P, Danielson SD (2001) Induction of resistance in field grown soybean by the bean leaf beetle, Cerotoma trifurcate (Forster) (Coleoptera: Chrysomelidae). J Kansas Entomol Soc $74: 112-114$

Stamp N (2003) Out of the quagmire of plant defense hypotheses. The Quaterly Review of Biology 78:23-55

Stout MJ, Workman J, Duffey SS (1994) Differential induction of tomato foliar proteins by arthropod herbivores. J Chem Ecol 20:2575-2594

Strauss SY, Irwin RE, Lambrix V (2004) Optimal defense theory and flower petal colour predict variation in the secondary chemistry of wild radish. J Ecol 92:132-141

Thaler JS, Stout MJ, Karban R, Duffey SS (1996) Exogenous jasmonates simulate insect wounding in tomato plants (Lycopersicon esculentum) in the laboratory and field. J Chem Ecol 22:1767-1781

Traw MB, Feeny P (2008) Glucosinolates and trichomes track tissue value in two sympatric mustards. Ecol 89:763-772

Underwood N (1998) The timing of induced resistance and induced susceptibility in the soybean-Mexican bean beetle system. Oecologia 114:376-381

Underwood N, Morris W, Gross K, Lockwood JR III (2000) Induced resistance to Mexican bean beetles in soybean: variation among genotypes and lack of correlation with constitutive resistance. Oecologia 122:83-89

Underwood N, Rausher M, Cook W (2002) Bioassay versus chemical assay: measuring the impact of induced and constitutive resistance on herbivores in the field. Oecologia 131(2):211-219

Underwood N, Anderson K, Inouye BD (2005) Induced vs. constitutive resistance and the spatial distribution of insect herbivores among plants. Ecology 86:594-602

Wackers FL, Bonifay C (2004) How to be sweet? Extrafloral nectar allocation by Gossypium hirsutum fits optimal defense theory predictions. Ecol 85:1512-1518

Waldbauer GP (1968) The consumption and utilization of food by insects. Adv Insect Physiol 5:229-288

Waldbauer GP, Friedman S (1991) Self-selection of optimal diets by insects. Annu Rev Entomol 36:43-63

Wallace SK, Eigenbrode SD (2002) Changes in the glucosinolatemyrosinase defense system in Brassica juncea cotyledons during seedling development. J Chem Ecol 28:243-256

Zangerl AR, Rutledge CE (1996) The probability of attack and patterns of constitutive and induced defense: a test of optimal defense theory. Am Nat 147:599-608

Zhu-Salzman K, Luthe DS, Felton GW (2008) Arthropod-inducible proteins: broad spectrum defenses against multiple herbivores. Plant Physiol 146:852-858 